\title{
Australian Journal of

\section{Morphological variations and relationship among onion germplasm for quantitative and qualitative traits at trans-Himalaya Ladakh, India}

\author{
Jagdish Singh Arya ${ }^{1 *}$, Narendra Singh ${ }^{1}$, Preeti Singh Arya ${ }^{2}$, Anil Kant ${ }^{3}$ \\ ${ }^{1}$ Defence Institute of High Altitude Research, Defence Research \& Development Organization, C/o 56 APO, Leh- \\ Ladakh (Jammu \& Kashmir) India-194 101 \\ ${ }^{2}$ Department of Biochemistry, Narendra Dev University of Agriculture and Technology, Kumar Ganj Faizabad \\ (Uttar Pradesh) India-224229 \\ ${ }^{3}$ Department of Biotechnology and Bioinformatics, Jaypee University of Information Technology, Waknaghat, \\ Solan (H.P.) India
}

\section{*Corresponding author: Jagdishsingh0482@gmail.com}

\begin{abstract}
In the present work, the variability, interrelationship, and divergence pattern of twenty six accessions of onion at high altitude were studied based on quantitative and qualitative traits. Multivariate analysis was used to classify the twenty six onion accessions. Cluster I contained two genotypes, cluster II contained ten genotypes, cluster III contained two and cluster IV contained twelve genotypes. The highest inter-cluster distance was observed between I and IV, and the lowest between I and II. The maximum intra-cluster distance was observed in Cluster II and the minimum in cluster III. The intra-cluster distance in all the four clusters was relatively low, indicating that genotypes within the same cluster were closely related. Based on cluster means, cluster 1 is the best in terms of number of leaves and neck thickness, cluster II best in terms of leaf width, Double/deformed bulb, Polar diameter, equatorial diameter, average bulb weight and bulb yield $\mathrm{kg} / \mathrm{plot}$, cluster III is the best in terms of days to maturity, TSS and dry matter content and cluster IV which is best in terms of plant height, leaf length and chlorophyll content. Considering cluster distance and cluster mean, the intra cluster distance revealed that the genotypes from the cluster II and genotypes from the cluster IV may be selected as parents for future breeding program. It was found that, PCA extracted three PCs and contributed $95.61 \%$ of the variation out of which PC1 accounted $77.52 \%$ variability, PC2 for $10.72 \%$ and PC $37.38 \%$ variability of the variance among 26 accessions. The greater part of the variance was accounted for by other traits such as average bulb weight, bulb yield, leaf length, equatorial diameter and TSS. The high diversity found in the accessions shows great potential for improving qualitative as well as quantitative traits in onion.
\end{abstract}

Keywords: Allium cepa L., morphological variation, germplasm, multivariate analysis.

Abbreviations: SD_Standard deviation; ANOVA_ analysis of variance; PH_Plant height; NL_Number of leaves; LL_Leaf length; LW_Leaf width; CC_Chlorophyll content; MD_Maturity days; D/DB_Double/deformed bulb; NT_Neck thickness; TSS_Total soluble solids; DM_Dry matter; PD_Polar diameter; ED_Equatorial diameter; BSI_Bulb shape index; ABW_Average bulb weight; BY_Bulb yield; PCA_Principle component analysis.

\section{Introduction}

A lot of work has been carried out on onion in India but not for the conditions prevailing in Ladakh. Therefore, due to lack of knowledge of good cultivation practices, planting material and genotypes, productivity is low in the region. Onion (Allium cepa L.) is one of the important crops and spices grown in India. Both mature and immature bulbs are used as vegetable and spices. The non-availability of required germplasms and instability in desirable traits brings a research gap in onion improvement programs. Farmers have been using local cultivars since a long time which do not have good quality, yield and even have the tendency to split. To overcome these problems twenty five onion accessions were introduced and a diversity study was carried out. In any crop improvement program, knowledge of various variability parameters and association among different traits in the base population are pre-requisite to initiate and execute selection for yield and other desired traits. Characters that determine economic variability in onion are polygenic in nature and highly influenced by the environment. To improve the yield through selection of better varieties, knowledge of the association of bulb yield with yield-contributing characters is very essential. However, knowledge of correlations among various characters and their relative contribution to the yield is useful for multiple traits selection. Genetic variability is the prerequisite of any effective breeding program. Breeding makes use of existing variability or genetic variability is created using different techniques (Singh, 2009). Diversity in plant genetic resources (PGR) offers plant breeders the opportunity to develop novel and better cultivars with desirable characteristics, which include both farmer-preferred traits (yield potential and large seed, etc.) and breeder preferred traits (pest and disease resistance and photosensitivity) (Govindaraj et al., 2015).

Long day types are high yielders but have poor shelf life whereas short day types have better shelf life with low yielding capacity (Singh et al., 2013). Hence, development of 
high yielding varieties with good quality traits is needed nowadays. To improve the yield through selection, information on the nature and magnitude of variability present in a population is an important prerequisite for starting the breeding program. Genetic diversity is essential to meet the diversified goals of plant breeding such as breeding for increasing yield, wider adaptation, desirable quality, pest and disease resistance. Selection of genetically diverse parents in any breeding program is of immense importance for successful recombination breeding (Arunachalam, 1981 and Akter et al., 2015.). Genetic divergence analysis estimates the extent of diversity existing among selected genotypes (Mondal, 2003). Precise information on the nature and degree of genetic diversity helps the plant breeder in choosing diverse parents for purposeful hybridization (Samsuddin, 1985). Improvement in yield and quality is normally achieved by selecting genotypes with desirable character combinations existing in nature or by hybridization. Parents identified on the basis of the divergence analysis would be more promising. Mohanty (2001a); Mohanty and Prusty (2002) have reported similar results in onion. When breeding for a particular set of growing conditions, it is extremely important to know the use of local populations, since in them the relationships among yield components are balanced and in harmony with the effects of the specific climatic and edaphic factors. Principal component analysis (PCA), one of the multivariate analysis methods, showed which of the traits were decisive in genotype differentiation (Kovacic, 1994). PCA enables easier understanding of impacts and connections among different traits by finding and explaining them. The present investigation is an attempt to assess the magnitude of genetic diversity in the bulb yield potential of onion accessions and to isolate the diverse ones according to their genetic affinity for future improvement programs.

To make use of existing variability for an efficient breeding program, it is necessary to characterize variability of the available germplasm for qualitative and quantitative traits and determine correlations among traits of interest. Considering the above facts, this study was conducted to determine the extent of natural variability that elicited in onion germplasm collected from the National Bureau of Plant Genetic Resources, New Delhi, India and to determine the correlation among quantitative traits to derive breeding strategies for development of high-yielding cultivars.

\section{Results and Discussion}

The germplasms were found to be rich in variability for all the studies characters. While non-significant difference was observed among the characters between both the years of study. The observation of data showed that the plant height ranged from 31.55 to $66.26 \mathrm{~cm}$ and 23.77 to $60.21 \mathrm{~cm}$ in both the years (Supplementary Table 2). The maximum plant height $(66.26 \mathrm{~cm}, 60.21 \mathrm{~cm})$ was found in IC- 0391544 in both the years. The minimum plant height $(31.55 \mathrm{~cm}, 23.77 \mathrm{~cm})$ was recorded in both the years. The data obtained for number of leaves per plant in onion genotypes have been tabulated in supplementary Table 2 . The data reveal that the number of leaves per plant ranged from 5.34 to 16.64 and 14.06 to 5.54 during 2013 and 2014, respectively. The highest number of leaves per plant $(16.64,14.06)$ was found in IC-0279582 in both the years. The minimum number of leaves per plant $(5.54,5.34)$ was obtained in IC-0588677 in both the years. Leaf length in onion genotypes ranged from 24.52 to 60.27 $\mathrm{cm}$ and from 24.29 to $57.54 \mathrm{~cm}$ during 2013 and 2014, respectively (Supplementary Table 2). The greatest leaf length $(60.27 \mathrm{~cm}, 57.54 \mathrm{~cm})$ was found in IC-0391544 in both the years. In IC-0588677, the smallest leaf length $(24.52 \mathrm{~cm}$, $24.29 \mathrm{~cm}$ ) was obtained in both the years. Leaf width ranged from 0.72 to $5.90 \mathrm{~cm}$ and 0.61 to $5.39 \mathrm{~cm}$ during2013 and 2014, respectively. In IC-0392640, greatest leaf width (5.90, $5.39 \mathrm{~cm})$ was found while lowest was $(0.72,0.62 \mathrm{~cm})$ in IC0279582 in both the years (Supplementary Table 3). The chlorophyll content ranged from 36.81 to 46.64 cci and 34.93 to 43.18 cci during 2013 and 2014. The maximum chlorophyll content $(46.64 \mathrm{cci}, 43.18 \mathrm{cci})$ was observed in IC0035940 whereas lowest $(36.81 \mathrm{cci}, 34.93 \mathrm{CCI})$ was observed in IC-0440229 during both the years (Supplementary Table 3 ). The results showed that the days to maturity ranged from 131.80 to 150.40 and 135 to 154.20 during 2013 and 2014 respectively (Supplementary Table 3 ). The maximum days to maturity $(150.40,154.20)$ was taken in IC-0038823 while minimum $(131.80,135)$ in IC-0374724 during both the years. The double and deformed bulbs resulted in deteriorating quality as well as shelf life. The double/deformed bulb ranged from 23.90 to 97.55 and 28.31 to 99.07 in 2013 and 2014 (Supplementary Table 4). The maximum double/deformed bulb $(97.55,99.06)$ was found in the Local Cultivar while minimum $(23.90,28.31)$ was found in IC0512324 during both the years. Thickness of the neck is an important parameter that determines the storability qualities of onion varieties. The onion genotype showed high variability in neck thickness. It ranged from 0.62 to $2.73 \mathrm{~cm}$ and 0.94 to $2.96 \mathrm{~cm}$ during the years 2013 and 2014, respectively (Supplementary Table 4). The greatest neck thickness $(2.73,2.96 \mathrm{~cm})$ was observed in IC-0392640 whereas the lowest $(0.62,0.94 \mathrm{~cm})$ was observed in IC0588677 during both the years. The Total soluble solid ranged from 6.82 to $14.06 \%$ and 9.20 to $16.25 \%$ during 2013 and 2014 respectively (Supplementary Table 4). The highest total soluble solids $(14.06,16.25 \%)$ was found in IC-0512324 whereas lowest $(6.82,9.20 \%)$ was found in IC-0338582 during the both years. The dry matter content ranged from 8.74 to $15.37 \%$ and 11.25 to $17.22 \%$ during the 2013 and 2014 seasons, respectively (Supplementary Table 5). The maximum dry matter content $(15.37,17.22 \%)$ was found in IC-0512324 while the lowest $(8.74,11.25 \%)$ in IC-0338582 in both the years. Polar diameter ranged from 2.60 to $7.22 \mathrm{~cm}$ and 2.15 to $6.83 \mathrm{~cm}$ during 2013 and 2014 respectively (Supplementary Table 5). Maximum polar diameter (7.22, $6.83 \mathrm{~cm}$ ) was found in IC-0338582. Minimum polar diameter $(2.60,2.15 \mathrm{~cm})$ was obtained in IC-0391544 in both the years. The equatorial diameter ranged from 2.40 to $7.02 \mathrm{~cm}$ and 2.05 to $6.63 \mathrm{~cm}$ during both the years respectively (Supplementary Table 5). The greatest equatorial diameter $(7.02,6.63 \mathrm{~cm})$ was obtained in IC-0392640 while smallest $(2.40,2.05 \mathrm{~cm})$ in IC-0035182 during both the years. The bulb shape index or the bulb dimensions are indirectly related to the yield and storage capacity of onion bulbs, bulb shape is an important selection criterion and the desired shape depends on the market preference. Kepkova and Uniocka (1970) reported that onions with a diameter of 3.5 to $4.5 \mathrm{~cm}$ stored better than those with a diameter of 4.5 to $7.0 \mathrm{~cm}$. Considerable variation was found in the bulb shape of onion genotypes. The shape can vary from flat to globe to torpedo with different markets having different requirements. Bulb shape has become an important aspect of market acceptability as well as ease in packaging. The onion bulb shape was assessed by using the bulb shape index; which is the ratio of the bulb height to diameter. The bulb shape index values of genotypes IC-0035856, IC-0035992, IC-0038823, IC- 
Table 1. The bulb shape index values of genotypes.

\begin{tabular}{|c|c|c|c|c|c|}
\hline S. no. & Genotypes & Value(2013) & Value(2014) & Bulb shape index & Shape \\
\hline \multirow[t]{11}{*}{1} & IC-0035856 & 0.92 & 0.94 & $<1$ & Flat \\
\hline & IC-0035992 & 0.99 & 0.98 & & \\
\hline & IC-0038823 & 0.81 & 0.78 & & \\
\hline & IC-0356095 & 0.90 & 0.87 & & \\
\hline & IC-0369521 & 0.93 & 0.90 & & \\
\hline & IC-0391544 & 0.77 & 0.70 & & \\
\hline & IC-0392640 & 0.86 & 0.83 & & \\
\hline & IC-0512324 & 0.80 & 0.75 & & \\
\hline & IC-0524211 & 0.81 & 0.72 & & \\
\hline & IC-0588677 & 0.89 & 0.91 & & \\
\hline & IC-0039039 & 0.85 & 0.75 & & \\
\hline \multirow[t]{8}{*}{2} & IC-0279582 & 1.13 & 1.05 & $>1$ & Torpedo \\
\hline & IC-0035182 & 1.31 & 1.21 & & \\
\hline & IC-0035851 & 1.20 & 1.14 & & \\
\hline & IC-0035940 & 1.22 & 1.30 & & \\
\hline & IC-0047928 & 1.09 & 1.05 & & \\
\hline & IC-0338582 & 1.06 & 1.08 & & \\
\hline & IC-0440229 & 1.28 & 1.22 & & \\
\hline & Local check & 1.20 & 1.13 & & \\
\hline \multirow[t]{6}{*}{3} & IC-0035891 & 1.04 & 1.05 & 1 & Globular \\
\hline & IC-0047940 & 1.01 & 1.02 & & \\
\hline & IC-0279180 & 1.01 & 0.93 & & \\
\hline & IC-0310990 & 1.01 & 0.98 & & \\
\hline & IC-0374706 & 1.03 & 1.02 & & \\
\hline & IC-0392647 & 1.01 & 1.03 & & \\
\hline
\end{tabular}

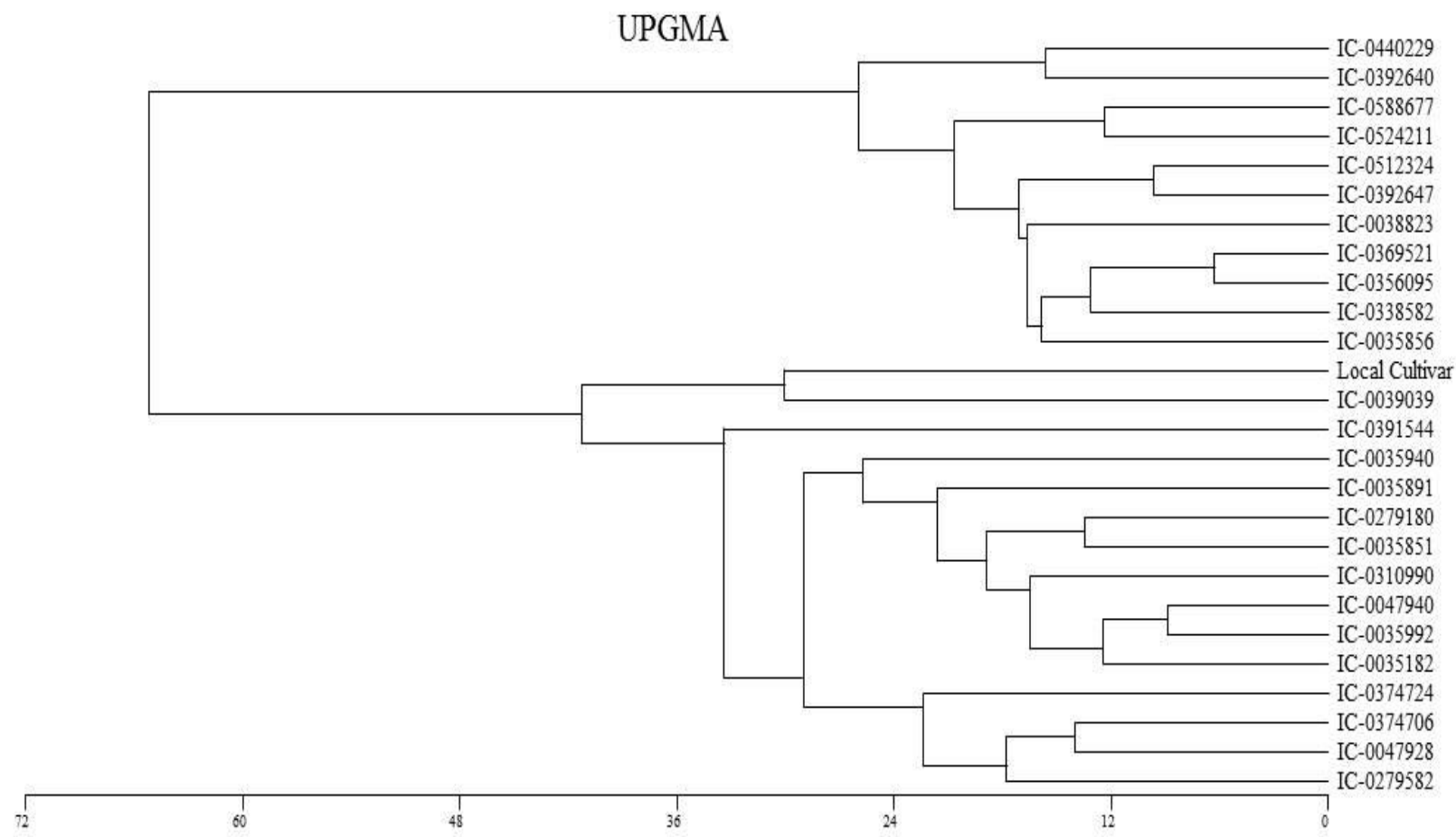

\section{Euclidean}

Fig 1. Dendogram showing the genotypic relationship among 26 accessions are based on morphological traits. 
Table 2. Qualitative traits of onion germplasm.

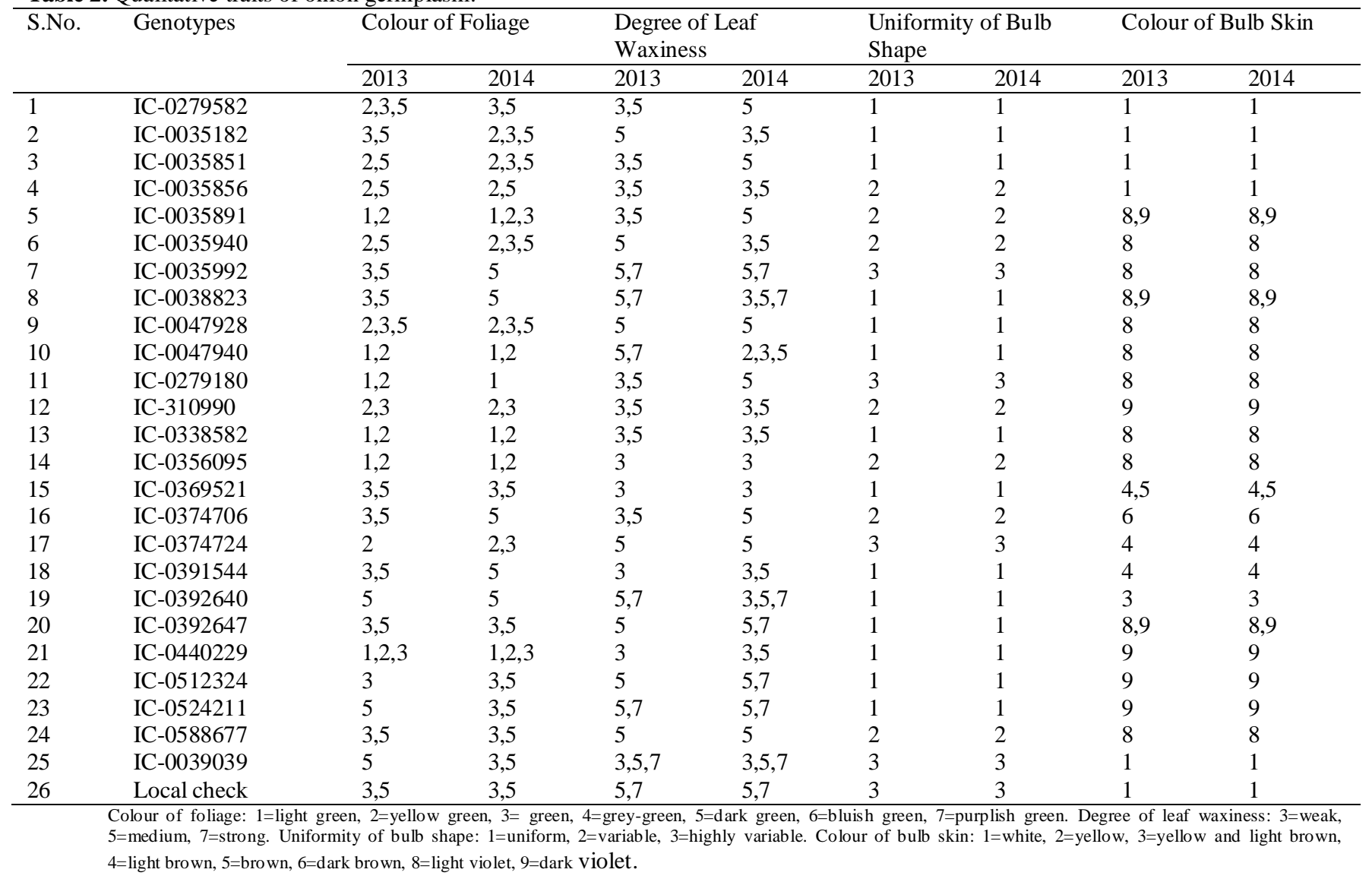

\section{PCA case scores on the basis of observed traits}

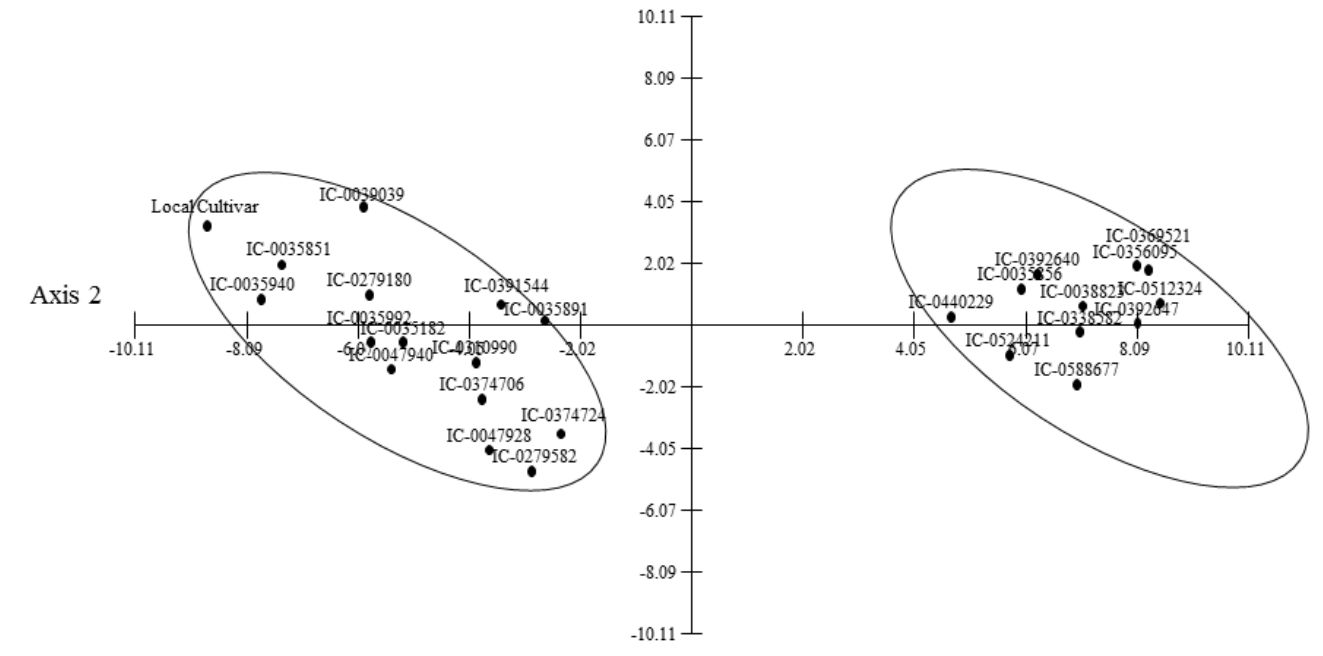

Axis 1

Fig 2. Principal Component analysis of morphological data with respect to 26 onion genotypes. 


\begin{tabular}{|c|c|c|c|c|c|c|c|c|c|c|c|c|c|c|c|}
\hline Traits & $\mathrm{PH}$ & NL & LL & LW & $\mathrm{CC}$ & MD & $\mathrm{D} / \mathrm{DB}$ & NT & TSS & DM & PD & ED & BSI & ABW & BY \\
\hline $\mathrm{PH}$ & 1 & $0.480^{* *}$ & $0.855^{* *}$ & $-0.197^{*}$ & $0.237^{* *}$ & $-0.244^{* *}$ & $0.450^{* *}$ & $0.342^{* *}$ & $-0.228^{* *}$ & $-0.224^{*}$ & $-0.523^{* * *}$ & $-0.523^{* * *}$ & $.218^{*}$ & $-0.454^{* * *}$ & $-0.451^{* * *}$ \\
\hline NL & & 1 & $0.416^{* *}$ & $-0.279^{* *}$ & -0.008 & $-0.419^{* *}$ & $0.238^{* *}$ & $0.395^{* *}$ & -0.019 & -0.041 & $-0.510^{* *}$ & $-0.522^{* *}$ & $.210^{*}$ & $-0.404^{* *}$ & $-0.405^{* *}$ \\
\hline LL & & & 1 & -0.084 & $0.275^{* *}$ & -0.160 & $0.411^{* *}$ & $0.410^{* * *}$ & $-0.182^{*}$ & -0.165 & $-0.464^{* *}$ & $-0.412^{* *}$ & .060 & $-0.352^{* *}$ & $-0.349^{* *}$ \\
\hline LW & & & & 1 & $0.290^{* *}$ & $0.514^{* *}$ & $-0.490^{* *}$ & $-0.207^{*}$ & 0.074 & 0.107 & $0.739^{* *}$ & $0.805^{* *}$ & $-.333^{* *}$ & $0.692^{* *}$ & $0.692^{* *}$ \\
\hline $\mathrm{CC}$ & & & & & 1 & $0.245^{* *}$ & -0.105 & $-0.364^{* *}$ & -0.116 & -0.155 & $0.193^{*}$ & $0.220^{*}$ & -.075 & $0.229^{* *}$ & $0.230^{* *}$ \\
\hline MD & & & & & & 1 & $-0.306^{* *}$ & $-0.481^{* *}$ & $-0.325^{* *}$ & $-0.317^{* *}$ & $0.665^{* *}$ & $0.699^{* *}$ & $-.242^{* *}$ & $0.597^{* *}$ & $0.597^{* *}$ \\
\hline $\mathrm{D} / \mathrm{DB}$ & & & & & & & 1 & $0.406^{* *}$ & $-0.183^{*}$ & -0.165 & $-0.582^{* * *}$ & $-0.628^{* *}$ & $.309^{* *}$ & $-0.726^{* *}$ & $-0.726^{* *}$ \\
\hline NT & & & & & & & & 1 & 0.022 & 0.046 & $-0.607^{* *}$ & $-0.534^{* *}$ & -.009 & $-0.570^{* *}$ & $-0.570^{* *}$ \\
\hline TSS & & & & & & & & & 1 & $0.978^{* *}$ & 0.029 & 0.091 & -.116 & $0.273^{* *}$ & $0.276^{* *}$ \\
\hline $\mathrm{DM}$ & & & & & & & & & & 1 & 0.043 & 0.102 & -.110 & $.267^{* *}$ & $0.269^{* *}$ \\
\hline PD & & & & & & & & & & & 1 & $0.907^{* *}$ & -.116 & $.817^{* *}$ & $0.816^{* *}$ \\
\hline ED & & & & & & & & & & & & 1 & $-.498^{* *}$ & $.885^{* *}$ & $0.885^{* *}$ \\
\hline BSI & & & & & & & & & & & & & 1 & $-.421^{* * *}$ & $-0.422^{* *}$ \\
\hline ABW & & & & & & & & & & & & & & 1 & $1.000^{* *}$ \\
\hline BY & & & & & & & & & & & & & & & 1 \\
\hline
\end{tabular}

${ }^{*}$ Correlation is signific ant at the 0.05 level (2-tailed). ${ }^{* *}$ Correlation is signific ant at the 0.01 level (2-tailed).

Table 4. Distribution of twenty six genotypes of onion in different clusters.

\begin{tabular}{|c|c|c|c|}
\hline Sr.no. & Cluster & $\begin{array}{l}\text { Number } \\
\text { genotypes }\end{array}$ & Genotypes \\
\hline 1 & I & 2 & IC-0392640, IC-0440229 \\
\hline 2 & II & 10 & $\begin{array}{l}\text { IC-0035856, IC-0338582, IC-0356095, IC-0369521, IC-0512324, IC-0588677, IC- } \\
\text { 0524211, IC-0374724, IC-0392647, IC-0038823 }\end{array}$ \\
\hline 3 & III & 2 & Local Cultivar, IC-0039039 \\
\hline 4 & IV & 12 & $\begin{array}{l}\text { IC-0035851, IC-0035940, IC-0374706, IC-310990, IC-0279582, IC-0035182, IC- } \\
\text { 0035891, IC-0035992, IC-0047928, IC-0047940, IC-0279180, IC-0391544 }\end{array}$ \\
\hline
\end{tabular}

Table 5. Average intra- (bold face) and inter-cluster distance $\left(\mathrm{D}^{2}\right)$ of 26 onion genotypes.

\begin{tabular}{llllll}
\hline Sr. no. & Clusters & I & II & III & IV \\
\hline 1 & I & 2.191 & & & \\
2 & II & 2.542 & 2.778 & & \\
3 & III & 4.933 & 3.649 & 2.064 & \\
4 & IV & 6.129 & 5.675 & 4.645 & 2.345 \\
\hline
\end{tabular}


Table 6. Mean values for four clusters based on fifteen morphological traits.

\begin{tabular}{llllll}
\hline Sr. no. & Traits & \multicolumn{5}{c}{ Clusters } \\
\hline & & I & II & III & IV \\
1 & Plant Height (cm) & 50.64 & 38.15 & 41.83 & 55.43 \\
2 & Number of Leaves & 12.90 & 8.43 & 12.87 & 12.86 \\
3 & Leaf Length (Cm) & 43.42 & 32.97 & 38.35 & 46.33 \\
4 & Leaf Width $(\mathrm{Cm})$ & 1.16 & 3.02 & 1.09 & 1.20 \\
5 & Chlorophyll content & 39.14 & 42.32 & 37.88 & 44.34 \\
6 & Days to maturity & 134.26 & 141.53 & 133.60 & 135.95 \\
7 & Double/Deformed Bulb (\%) & 53.38 & 27.90 & 38.03 & 70.86 \\
8 & Neck Thickness $(\mathrm{cm})$ & 1.02 & 1.04 & 1.74 & 1.53 \\
9 & TSS \% & 7.90 & 9.40 & 12.48 & 8.58 \\
10 & Dry matter \% & 9.83 & 11.37 & 14.18 & 10.32 \\
11 & Polar adiameter $(\mathrm{cm})$ & 3.13 & 5.93 & 3.60 & 3.36 \\
12 & Equatorial Diameter $(\mathrm{Cm})$ & 3.06 & 6.43 & 3.43 & 2.89 \\
13 & Bulb shape index & 1.03 & 0.92 & 1.07 & 1.17 \\
14 & Average bulb wt. $(\mathrm{g})$ & 42.94 & 92.55 & 70.50 & 36.48 \\
15 & Bulb yield kg/ plot & 8.57 & 18.52 & 14.14 & 7.36 \\
\hline
\end{tabular}

Table 7. Eigenvalues and Variable lodging.

\begin{tabular}{llll}
\hline & PC 1 & PC 2 & PC 3 \\
\hline Eigenvalues & 1014.28 & 140.27 & 96.54 \\
Percentage & 77.52 & 10.72 & 7.38 \\
Cum. Percentage & 77.52 & 88.24 & 95.61 \\
Variables & PC 1 & PC 2 & PC 3 \\
Plant Height (cm) & -0.2 & 0.17 & 0.009 \\
Number Of Leaves & -0.042 & -0.044 & 0.067 \\
Leaf Length (Cm) & -0.158 & 0.216 & 0.61 \\
Leaf Width (Cm) & 0.023 & 0.024 & 0.013 \\
Chlorophyll content & 0.011 & 0.046 & 0.033 \\
Days to maturity & 0.085 & 0.166 & -0.019 \\
Double/Deformed Bulb (\%) & -0.546 & 0.037 & -0.368 \\
Neck Thickness(cm) & -0.011 & -0.006 & 0.015 \\
TSS \% & 0.021 & 0.014 & 0.692 \\
Dry matter \% & 0.02 & 0.019 & 0.01 \\
Polar adiameter (cm) & 0.036 & 0.025 & -0.021 \\
Equatorial Diameter (Cm) & 0.046 & 0.742 & -0.016 \\
Bulb shape index & -0.002 & -0.002 & -0.001 \\
Average bulb wt. (g) & 0.773 & 0.567 & 0.048 \\
Bulb yield kg/ plot & 0.155 & 0.114 & 0.012 \\
Colour of foliage & -0.002 & 0.013 & 0.054 \\
Degree of leaf Waxiness & -0.008 & -0.012 & -0.002 \\
Uniformity of Bulb shape & -0.011 & 0.015 & -0.032 \\
Colour of bulb skin & 0.034 & -0.063 & 0.002 \\
\hline
\end{tabular}

0356095, IC-0369521, IC-0391544, IC-0392640, IC0512324, IC-0524211, IC-0588677, IC-0039039 were found to be less than 1 , considered as flat (Table 1) while IC0279582, IC-0035182, IC-0035851, IC-0035940, IC0047928, IC-0338582, IC-0440229 and Local check were found to be more than 1, considered as torpedo. The bulb shape index values of genotypes IC-0035891, IC-0047940, IC-0279180, IC-0310990, IC-0374706, IC-0392647 were found to be 1 (Table 1), considered as globular. Average bulb weight ranged from 33.82 to $98.57 \mathrm{~g}$ and 31.20 to $93.56 \mathrm{~g}$ during both the years (Supplementary Table 6). Maximum average bulb weight $(98.57,93.56 \mathrm{~g}$ ) was found in IC0512324. Minimum average bulb weight $(33.82,31.20 \mathrm{~g})$ was obtained in IC-0035851 in both the years. The results showed that the bulb yield ranged from 6.69 to $19.97 \mathrm{~kg}$ and 6.11 to $18.72 \mathrm{~kg}$ during 2013 and 2014, respectively (Supplementary Table 6). The highest bulb yield (19.97, $18.72 \mathrm{~kg} / \mathrm{plot}$ ) was found in IC-0512324 and minimum (6.69, $6.11 \mathrm{~kg} / \mathrm{plot}$ ) in IC-0035851 respectively in both the years.

Among the 26 onion genotypes studied, considerable variation was observed for all the important attributes viz. colour of foliage, degree of leaf waxiness, uniformity of bulb shape and colour of bulb skin under the study. The characterization of onion varieties is presented in Table 2 . However, no significant difference was found between both the years.

The difference between studied genotypes might be related to genetic makeup by the used cultivars as per Kandil et al., (2010). Similar results were obtained by Akhtar (2002); Gemma et al., (2007); Soleymani and Shahrajabian (2012).

\section{Correlation analysis among quantitative traits}

Simple correlations between characteristics are shown in Table 3. Leaf width $\left(\mathrm{r}=0.692^{* *}\right)$, chlorophyll content $\left(\mathrm{r}=0.230^{* * *}\right)$, days to maturity $\left(\mathrm{r}=0.597^{* *}\right)$, TSS $\left(\mathrm{r}=0.276^{* * *}\right)$, dry matter $\left(\mathrm{r}=0.269^{* *}\right)$, polar diameter $\left(\mathrm{r}=0.816^{* * *}\right)$ and equatorial diameter $\left(\mathrm{r}=0.885^{* * *}\right)$ have significantly high positive correlation with the bulb yield while plant height ($\left.0.451^{* *}\right)$, number of leaves $\left(-0.405^{* *}\right)$, leaf length ($\left.0.349^{* *}\right)$, double/deformed bulb $\left(\mathrm{r}=-0.726^{* *}\right)$, neck thickness $(\mathrm{r}=-0.570 * *)$ and bulb shape index $(\mathrm{r}=-0.422 * *)$ have significantly high negative correlation. These characters could not be considered in selection criteria owing to their 
negative effect on bulb yield suggesting that the selection of these characters may not help in increasing the bulb yield. This result was in agreement with that reported by Mohanty (2001b); Rahman et al., (2002); Trivedi et al., (2006); Yaso (2007).

\section{Cluster analysis}

Based on the D2 value estimates of genetic divergence the 26 onion genotypes were grouped into four distinct clusters (Fig1, Table 4). A wide range of diversity was observed in the

experimental material for the majority of the characters studied. Cluster IV consisted of a maximum of 12 genotypes, Cluster II consisted of 10 genotypes, cluster I consisted of 2 genotypes and cluster II also consisted of 2 genotypes.

Cluster II had the highest intra-cluster distance (2.778) followed by cluster IV (2.345), cluster I (2.191) and cluster III (2.064) Table 5. The intra cluster distance in all the four clusters was essentially low, indicating that genotypes within the same cluster were closely related. While considering the inter-cluster distance (Table 5), maximum inter-cluster distance (6.129) was noticed between I and IV followed by (5.675) between II and IV and (4.933) between I and III. Minimum distance (2.542) was noticed between I and II (Table 5). According to Ghaderi et al. (1984), increasing parental distance implies a great number of contrasting alleles at the desired loci, and to the extent that these loci recombine in the F2 and F3 generation following a cross of distantly related parents, the greater will be the opportunities for the effective selection of yield factors. Thus, the crossing of genotypes from these clusters with other clusters may produce higher amounts of heterotic expression in the first filial generations (F1's) and a wide range of variability in subsequent segregating (F2) populations. Similar results were found by Akter et al., 2015.

Based on cluster means (Table 6); the important cluster was I for number of leaves (12.90)and neck thickness $(1.02 \mathrm{~cm})$, Cluster II for leaf width $(3.02 \mathrm{~cm})$, double/deformed bulb $(27.90 \%)$, polar diameter $(5.93 \mathrm{~cm})$, equatorial diameter $(6.43 \mathrm{~cm})$, average bulb weight $(92.55 \mathrm{~g})$ and bulb yield $\mathrm{kg} /$ plot (18.52 kg/plot), Cluster III for days to maturity (133.60), TSS $(12.48 \%)$ and dry matter $(14.18 \%)$ and Cluster IV for plant height $(55.43 \mathrm{~cm})$, leaf length $(46.43 \mathrm{~cm})$ and chlorophyll content (44.34 cci).

On the basis of results; it can be concluded that genotypes that belong to cluster I are suitable for number of leaves and neck thickness. The suitable genotypes for leaf width, double/deformed bulb, polar diameter, equatorial diameter, average bulb weight and bulb yield $\mathrm{kg} / \mathrm{plot}$ belonged to cluster II. Genotypes which belonged to cluster III are suitable for days to maturity, TSS and dry matter content and cluster IV which was suitable for plant height, leaf length and chlorophyll content could be selected as a parent for the hybridization program. Crosses involving parents belonging to more divergent clusters would be expected to manifest maximum heterosis and wide variability in genetic architecture (Singh et al., 1987; Akter et al., 2015.).

In the present study, Cluster II was found to be more divergent than the others. However, the chance of getting segregates with high bulb yield level is quite limited when one of the characters has a very low content/yield level. The selection of parents should also consider the special advantage of each cluster and each genotype within a cluster depending on the specific objective of hybridization (Chahal and Gosal, 2012). Thus, crosses involving Cluster II with any other cluster are suggested to exhibit high heterosis and could result in segregates with higher bulb yield.

\section{Multivariate analysis}

A Dendrogram was constructed to display the similarity between morphological relationships among different genotypes of onion based on the Euclidean distance from the morphological data matrix of two consecutive years. All genotypes were represented in four clusters (Fig. 1). Dendrogram based on UPGMA method analysis grouped the genotype into main clusters I, II, III and IV. Cluster I represents the genotypes IC-0392640 and IC-0440229, cluster II represents IC-0035856, IC-0338582, IC-0356095, IC-0369521, IC-0512324, IC-0588677, IC-0524211, IC0374724, IC-0392647, IC-0038823, Cluster III represents Local Cultivar and IC-0039039 and cluster IV represents the genotypes IC-0035851, IC-0035940, IC-0374706, IC310990, IC-0279582, IC-0035182, IC-0035891, IC-0035992, IC-0047928, IC-0047940, IC-0279180, , IC-0391544. These initial groupings of the individuals show the best fit to the four distinct groups, but we could not determine which characters are responsible for these groupings. Therefore, we had to do further statistical evaluation with principal component analysis (PCA).

PCA reflects the importance of the largest contributor to the total variation at each axis of differentiation (Sharma, 1998). The eigen values are often used to determine how many factors are to be retained. The sum of the eigen values is usually equal to the number of variables. We analyzed the PCA for 19 variables to discriminate the 26 onion varieties along with the local check. We found that PCA extracted three PCs and contributed $95.61 \%$ of the variation out of which PC1 explained $77.52 \%$ variability, PC2 $10.72 \%$ and PC3 $7.38 \%$ variability. Suggesting these principal component scores might be used to summarize the original 19 variables in any further analysis of the data. According to Chahal and Gosal (2012) characters with the largest absolute value closer to unity within the first principal component influence the clustering more than those with lower absolute value closer to zero. Therefore, in the present study, differentiation of the accessions into different clusters was because of relatively high contribution of few characters rather than small contribution from each character.

Accordingly, PC1 had high positive component loading from the average bulb weight, bulb yield and high negative loading from the leaf length, double/deformed bulb while remaining traits in $\mathrm{PC} 1$ did not contribute; rather their effects were distributed among other PCs (Table 7). The positive and negative loading showed the presence of positive and negative correlation trends between the components and the variables. Therefore, the above mentioned characters which loaded highly positively or negatively contributed more to the diversity and they were the ones that were most differentiated (Table 7). The traits which contributed more positively to PC2 were leaf length, equatorial diameter, average bulb weight (Table 4) however, remaining traits in PC2 did not contribute. Rather, their effects were distributed among other PCs. In PC3, the traits which contributed more positively to PC3 were TSS, leaf length and high negative loading from double /deformed bulb while remaining traits in PC3 did not contribute; their effect were distributed among other PCs.

The configuration of the twenty six onion genotypes along with Local Cultivar are shown in Fig 2. The coordination of the genotypes on all the axes together revealed that genotypes IC-0512324, IC-0392647, IC-0392640, IC-0369521, IC0356095, IC-0038823, IC-0035856, IC-0588677, IC- 
0524211 and IC-0338582 were the most distinct genotypes for the characters studied. Usually it is customary to choose one variable from these identified groups. Hence, for the first group average bulb weight is best choice, which had the largest loading from component one, equatorial diameter for the second, and TSS for the third group (Table 7). The average bulb weight had discriminating ability to 10 genotypes from the 26 ones. This suggests that our PCAs determine characters responsible for individual discrimination. The characters which contributed positively to first three principal components could be given due consideration while selecting the best genotypes without losing yield potential.

\section{Materials and Methods}

\section{Experimental site}

Ladakh is a high-altitude cold desert having distinct geographical and climatic conditions and is considered one of the most difficult terrains in the world; altogether offering a tough life with a lack of resources. The experiment was conducted from May to October in 2013 and 2014 in the Vegetable Research Unit at the Defence Institute of High Altitude Research, Leh-Ladakh, (altitude $3500 \mathrm{~m}$ above MSL, latitude $34^{\circ} 8^{\prime} 16.119^{\prime \prime} \mathrm{N}$, longitude 77³4'19.2216"E). The soil texture of the experimental site was silty loam with $\mathrm{pH} 7.1 \pm 0.2$. Organic carbon and organic matter content were $1.2 . \pm 0.4 \%$ and $4.2 \pm 0.5 \%$, respectively.

\section{The experimental material}

The experimental material consisted of 26 accessions including a local cultivar (Supplementary Table 1) of onion viz. IC-0279582, IC-0035182, IC-0035851, IC-0035856, IC-0035891, IC-0035940, IC-0035992, IC-0038823, IC0047928, IC-0047940, IC-0279180, IC-310990, IC-0338582, IC-0356095, IC-0369521, IC-0374706, IC-0374724, IC0391544, IC-0392640, IC-0392647, IC-0440229, IC0512324, IC-0524211, IC-0588677, IC-0039039 and Local Cultivar having a broad spectrum of variation which was obtained from NBPGR New Delhi.

\section{Experimental procedure and observations}

The experiment was laid down in randomized complete block design (RCBD) with five replications and one local check; all the recommended agronomic practices and plant protection measures were followed. The observations were recorded from ten randomly selected plants from each accession in each replication for thirteen quantitative characters viz., Plant Height (CM), Number of leaves per plant, Leaf Length (CM), Leaf width (CM), Chlorophyll Content (CCI), Neck Thickness (CM), Total Soluble Solids (\%), Dry Matter (\%), Polar Diameter (CM), Equatorial Diameter (CM), Bulb Shape Index, Average Bulb Weight (g) and Bulb Yield (Kg/Plot) and four qualitative traits viz., Colour of Foliage, Degree of Leaf Waxiness, Uniformity of Bulb Shape, Colour of Bulb Skin. All four qualitative traits were interpreted as per the method of Ekhvaia and Akhalkatsi (2010). The traits were observed as per International Plant Genetic Resources Institute (IPGRI) plant descriptors for Allium species. Mean values of all observations were calculated for quantitative traits and subjected to analysis carried out by SPSS 21 statistical analysis software.

\section{Statistical analysis}

Morphological variations and relationship among onion germplasms in relation to quantitative and qualitative traits on the studied parameters were analyzed using $\mathrm{D}^{2}$ statistics (Mahalanobis, 1936).

One way ANOVA with 2-sided Tukey's HSD at $p \leq 0.05$ was carried out using SPSS 21.0The data of both years was pooled due to non-significant variation and subjected to PCA Principal component analysis (PCA) was used to ordinate population means allowing for variance and covariance among genotypes within the population (kim, 1975). Average Euclidean distance was calculated for each population and the resulting distance matrix was used to construct a dendrogram using UPGMA method (Mohammadi and Prasanna, 2003)

\section{Conclusion}

The present investigation provides considerable information useful in the genetic improvement of onion. Genotypes were grouped into cluster I, II, III and IV. The maximum intercluster diversity was observed among the genotypes grouped into cluster I and IV. From cluster mean values, genotypes in Cluster II, III and IV deserve consideration for their direct use as parents in hybridization programs to develop high yielding onion varieties. There is significant genetic variability among the tested genotypes that provides an excellent opportunity to bring about improvement through wide hybridization by crossing genotypes in different clusters. Further studies on the influence of environment and agronomic practices on the genetic potential of the varieties in different environment are necessary. This is helpful to stratify the environments based on quality and yield stability, generally, leading to the development of onion varieties possessing equatorial diameter, polar diameter, average bulb weight, better T.S.S. and yield.

\section{Acknowledgement}

The authors are grateful to Defence Institute of High Altitude Research, DRDO, Leh -Ladakh (J\&K), India for providing financial support to carry out this work and Ritendra Mishra for proofreading of the paper.

\section{References}

Akhtar ME, Khurran B, Khan MZ, Khakhar KM (2002) Effect of potash application on yield of different varieties of onion (Allium cepa L.). Asian J Plant Sci. 1(4):324-325.

Akter MS, Biswas A, Siddique SS, Hossain S, Ivy NA (2015) Estimation of genetic diversity in Onion (Allium cepa L.). The Agriculturists. 13(1):26-34.

Arunachalam G (1981) Genetic distances in plant breeding. Indian J Genet. 41:226-236.

Chahal, GS, Gosal SS (2012) Principles and procedures of plant breeding. In: Biotechnology and conventional approaches, $5_{\text {th }}$ edn. Narosa publishing house, New Delhi. 132

Ekhvaia E, Akhalkatsi M (2010) Morphological variation and relationships of Georgian populations of Vitis vinifera L. subsp. sylvestris (C.C. Gmel.) Hegi Flora. 205:608-617.

Gemma AC, Terry LA, White PJ (2007) Effect of controlled atmosphere storage on abscisic acid concentration and other biochemical attribute of onion bulbs. Postharvest Biol Tec. 39:233-242. 
Ghaderi A, Adams MW, Nassib AM (1984). Relationship between genetic distance and heterosis for yield and morphological traits in dry edible bean and faba bean. Crop Sci. 24:37-42.

Govindaraj M, Vetriventhan M, Srinivasan M (2015) Importance of genetic diversity assessment in crop plants and its recent advances: An overview of its analytical perspectives. Genet Res Int. 2015(1).

Kandil AA, Leilah AA, Mostafa AK, Fathalla FH (2010) Study on the internal bulb quality of some new Egyptian onion cultivars under different irrigation regimes. Int J Plant Prod. 1(2):205-212.

Kepkova A, Uniocka I (1970) The effect of onion size and number per package on storage under different conditions. Biul Warzywniczy. 11:355-371.

Kim J (1975) Factor analysis. In statistical package for the social sciences. In: edn. Nie NH, Hull CH, Jenkins JG, Steinbrunner K and Bent HD. McGraw-Hill, New York. 468-514.

Kovacic Z (1994) Multivariate analysis. Faculty of economics. University of Belgrade (Serbian). 293.

Mahalanobis, PC (1936) A study on the generalized distance in statistics. Proceedings of national institute of science, India. 2:49-55.

Mohammadi SA, Prasanna BM (2003) Analysis of genetic diversity in crop plants-salient statistical tools and considerations. Crop Sci. 43:1235-1248.

Mohanty BK (2001a) Analysis of genetic divergence in kharif onion. Indian J Hortic. 58:260-263.

Mohanty BK (2001b) Genetic variability, inter relationship and path analysis in onion. J Trop Agr. 39(1):17-20.

Mohanty BK, Prusty AM (2002) Mahalanobis generalized distance analysis in onion. Crop Res. 3(1):142-144.

Mondal MA (2003) Improvement of potato (Solanum tuberosum L.) through hybridization and in vitro culture technique Ph.D. Thesis, Rajshahi University, Rajshahi, Bangladesh.
Rahman MA, Saha SR, Salam MA, Masum ASMH, Chowdhury SS (2002) Correlation and path coefficient analysis in onion (Allium cepa L.). J Biol Sci. 2(8):533 53.

Samsuddin AK (1985) Genetic diversity in relation to heterosis and combining analysis in spring wheat. Theor Appl Genet. 70:306-308.

Sharma JR (1998) Statistical and biometrical techniques in plant breeding. 1st edn. New age international publishers, New Delhi. 432.

Singh BD (2009) Plant breeding. In: Principles and methods, 7th edn. Kalyani publishers, New Delhi. 8

Singh SK, Singh RS, Maurya DM, Verma OP (1987) Genetic divergence among lowland rice cultivars: Annual report of Indian agricultural research institute (IARI), New Delhi, India.

Singh SR, Ahmed N, Lal S, Ganie SA, Amin M, Jan N, Amin A (2013) Determination of genetic diversity in onion (Allium cepa L.) by multivariate analysis under long day conditions. Afr J Agric Res. 8(45):5599-5606.

Soleymani A, Shahrajabian MH (2012) Effects of different levels of nitrogen on yield and nitrate content of four spring onion genotypes. Int J Agric Crop Sci. 4(4):179-182.

Trivedi AP, Dhumal KN, Lawande KE (2006) Estimates of heritability, genetic advance and correlation. Indian $\mathrm{J}$ Genet Pl Br. 66 (1):59-60.

Yaso IAA (2007) Performance and genetic parameters for six onion genotypes in Nubaria area. Egypt J Pl Br. 11(3):307318. 